\title{
Systematic review of rectal foreign bodies in older men: humanistic care and a novel challenge for society
}

\author{
Zhenyu Yang"^^, Peiyuan Xin", Shuai Zhou", Chuxin Zhou", Xianli He, Guoqiang Bao \\ Department of General Surgery, Tangdu Hospital, Air Force Medical University, Xi'an, China \\ Contributions: (I) Conception and design: G Bao, X He; (II) Administrative support: X He; (III) Provision of study materials or patients: Z Yang; \\ (IV) Collection and assembly of data: Z Yang, S Zhou; (V) Data analysis and interpretation: P Xin, C Zhou; (VI) Manuscript writing: All authors; \\ (VII) Final approval of manuscript: All authors. \\ "These authors contributed equally to this work. \\ Correspondence to: Guoqiang Bao; Xianli He. Department of General Surgery, Tangdu Hospital, Air Force Medical University, No. 569 Xinsi Road, \\ Xi'an 710038, China. Email: guoqiang@fmmu.edu.cn; wanghe@fmmu.edu.cn.
}

Background: In recent years, rectal foreign bodies have become a common proctological emergency in the male population, especially older Chinese men, often requiring surgical intervention due to associated complications. This review aimed to describe the epidemiology and clinical characteristics of rectal foreign bodies in older men and examine the possible challenges presented by the condition to clinicians and society. Methods: A comprehensive search was conducted in English-language databases and Chinese databases from January 2000 to December 2020. Studies concerning rectal foreign bodies were considered for this review if they reported the reason for a foreign body being in the rectum and related treatment measures. Contemporaneous rectal foreign bodies case data from General Surgery Department of Tangdu Hospital were also analyzed. According to differences in ethnicity, the older male patients were divided into a Chinese group and a non-Chinese group, and the parameters of the two groups were analyzed using statistical methods.

Results: A total of 159 studies were retrieved in an initial database search using "rectal foreign body" as the search term. These included 86 Chinese studies and 73 English-language studies. Collectively, these studies included 582 older male patients, 276 of whom were Chinese, and 307 who were non-Chinese. According to their source, the rectal foreign bodies were classified into 3 categories. The most common reason for a foreign body in the rectum was insertion for erotic purposes, with everyday articles accounting for most foreign body types. Sexual articles were mainly found to have been used in the pursuit of pleasure. There were no significant differences in foreign body sources, sizes, types, treatment selections, and outcomes between the two groups.

Discussion: Emergency hospital visits by older men with rectal foreign bodies due to erotic and sexual needs and practices are increasing. Although the sources, sizes, and types of foreign bodies were different, and patients recovered well after active and appropriate clinical treatment, the sexual needs of older men are a social issue that requires attention. Acknowledging and dealing with sexual issues is a multidimensional task that requires a collaborative effort to ensure a more humanistic approach to older patients.

Keywords: Rectal foreign bodies; older men; erotic purposes; sexual behavior; treatment

Submitted Dec 13, 2021. Accepted for publication Feb 16, 2022.

doi: $10.21037 /$ atm-22-103

View this article at: https://dx.doi.org/10.21037/atm-22-103

^ ORCID: 0000-0003-1458-6834. 


\section{Introduction}

Aging populations have become a social concern for countries worldwide. The global population, including that of China, a developing country with the largest population base, is experiencing a demographic shift, with the proportion of older adults (aged $\geq 60$ years) growing faster than any other age group (1). Older men, in particular, have experienced changes in their societal and familial roles and often have to face changes in psychological cognition. Previous studies have often focused on empty-nesters, the widowed elderly, psychological problems, and service teams for the elderly, among other issues, while discussion about sexuality and intimacy, particularly in older adults, has been sparse (2).

Discussions about sexuality in health care have slowly increased in recent years, as has the degree of social openness and cultural tolerance. People can acquire greater knowledge about sex through the new media, which also cater to the specific sexual needs of some older men. While it is generally assumed that sexuality diminishes with age, studies suggest that sexual interest and activity last well into the eighth decade of life (3).

Older members of society who are financially secure and have met their basic survival needs do not need to worry about basic life issues and, consequently, have more time to think about other issues, such as sex. A previous study pointed out that some older men have sexual needs that are often ignored by society and that, in certain circumstances, are likely to lead to high-risk sexual behaviors (4). Some of them address their sexual needs by trying a variety of sexual behaviors. For example, some try to obtain physical and psychological pleasure by inserting foreign objects into the anus. There have also been a few reports of retained rectal foreign bodies in older patients (60-80 years old) who had attempted to self-treat fecal impaction or to give themselves a prostate massage $(5,6)$, and some older men have been found to develop a sense of dependency after receiving prostate massage for chronic prostatitis (7). For these reasons, more and more elderly male patients are being admitted to hospitals for rectal foreign bodies that they cannot remove by themselves (8).

According to the literature, the incidence of masturbatory rectal foreign bodies has increased in recent years, and sexual gratification is now the most common cause of rectal foreign bodies (9), with $75 \%$ of the cases of rectal foreign bodies owing to a desire for erotic stimulation (8).

In light of the increasing numbers of hospital admissions for rectal foreign bodies in older men at Tangdu Hospital, the following review was undertaken to summarize the relationship between rectal foreign bodies and the sexual needs of older male patients. We attempted to raise social awareness of this particular group of men by evaluating the differences between older Chinese and non-Chinese male patients with rectal foreign bodies and analyzing their sexual behavior and psychological characteristics.

We present the following article in accordance with the PRISMA reporting checklist (available at https://atm. amegroups.com/article/view/10.21037/atm-22-103/rc).

\section{Methods}

\section{Search strategy}

A comprehensive search was conducted in English-language databases (PubMed, Embase, Web of Science, the Cochrane Library) and Chinese databases (CNKI, Wanfang, VIP, the Chinese Biomedical Database) from January 2000 to December 2020. The following search terms used were: ("foreign bodies" OR "foreign matter") AND ("rectum" OR "anus"). Clinical data from cases of rectal foreign bodies at Tangdu Hospital during the same period were also collected.

\section{Study selection}

For inclusion in this review, studies had to meet the following inclusion criteria: (I) the study was a case report or clinical study; (II) the study participants were male and over 60 years of age; (III) the study participants had complete medical records.

The exclusion criteria were as follows: (I) the study was a repeat study by the same authors; (II) the study was a meta-analysis of related articles; (III) the study included misdiagnoses of rectal foreign bodies, such as a rectal tumor being misdiagnosed as a rectal foreign body.

\section{Data extraction and outcome indicators}

The following data were extracted and recorded in a spreadsheet: (I) the first author, publication year, publication form, region, and number of cases; (II) the patient characteristics, foreign body sources, sizes, types, treatment selections, and outcomes.

\section{Statistical analysis}

The analysis was carried out using pair-wise comparison 


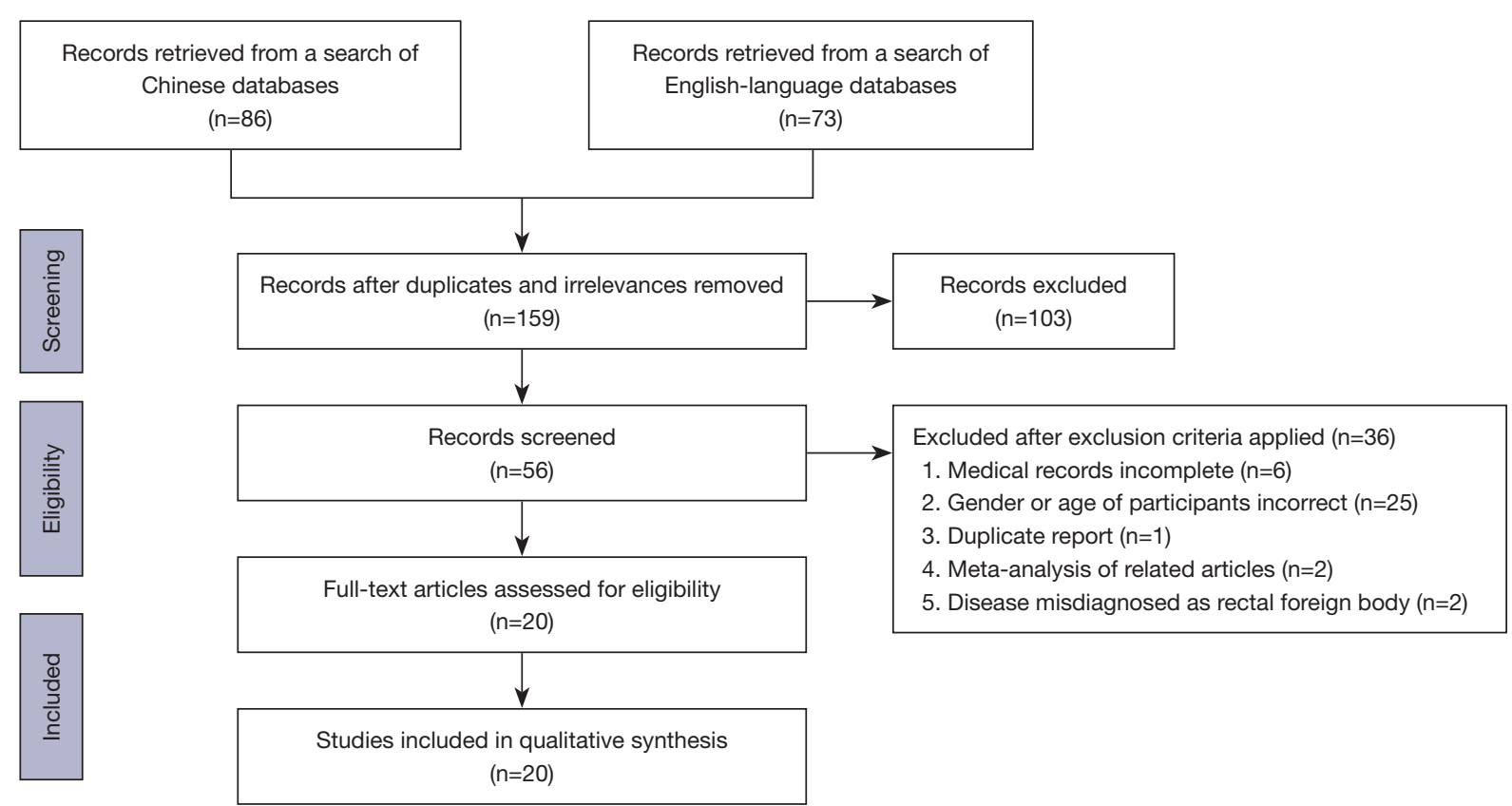

Figure 1 Flowchart of the study selection process.

between Chinese and non-Chinese arms. The general information of the patient, the characteristics of foreign body and the way of disposal were collected and presented in EXCEL. The Cochran's $Q$ test (chi-square statistic; $\chi^{2}$ ) was applied to evaluate the heterogeneity among studies and with a $\mathrm{P}<0.05$ signifying a significant difference between the Chinese group and non-Chinese group. Data statistical analysis was performed using Review Manager version 5.3 software.

\section{Ethical statement}

Written informed consent was obtained from all study participants. This study was approved by the Ethics Committee of the Tangdu Hospital of Air Force Medical University (No. K202009-03) and conducted according to the Declaration of Helsinki (as revised in 2013).

\section{Results}

\section{Study selection and patient's characteristics}

A total of 159 studies were retrieved in an initial literature search using "rectal foreign body" as the search term. These included 86 Chinese studies and 73 English-language studies. Collectively, these studies included a total of 737 patients. Of these, 582 (79\%) were male. The 737 patients were classified as Chinese $(\mathrm{n}=276)$, all of whom were males, and non-Chinese $(n=461)$, of whom 307 were male, and 154 were female. The sources of foreign bodies were divided into three categories: those inserted through the anus (anal), those swallowed and then retained in the rectum (oral), and those caused by improper medical practices (medical). The first of these categories accounted for most rectal foreign bodies, while the second category was more common in children under 10 years old and older female patients. Only 1 case was iatrogenic.

The process for identifying and selecting the relevant studies according to the inclusion and exclusion criteria is shown in Figure 1. After screening the titles or abstracts and retrieving the full texts, 20 studies, including 15 Chinese studies (10-24) and 5 English-language studies (7,25-28), published between 2000 and 2020 met the inclusion criteria, and a total of 35 male patients were analyzed for this systematic review, including 20 Chinese patients with an age range of $70.70 \pm 6.76$ years, and 15 non-Chinese patients with and age range of $70.83 \pm 7.14$ years. The full text of all the included studies was available. The characteristics of the selected studies are shown in Table 1.

\section{Types of rectal foreign bodies}

The types of rectal foreign bodies were classified into the 
Table 1 General characteristics of the patients, foreign bodies, extraction methods, and complications

\begin{tabular}{|c|c|c|c|c|c|c|c|c|c|c|c|c|}
\hline Study & Year & Cases & $\begin{array}{c}\text { Age } \\
\text { (years) }\end{array}$ & $\begin{array}{l}\text { Marital } \\
\text { status }\end{array}$ & Cause & $\begin{array}{l}\text { Medical } \\
\text { history }\end{array}$ & Source & Foreign body & Size $(\mathrm{cm})$ & $\begin{array}{c}\text { Hours after } \\
\text { insertion }\end{array}$ & $\begin{array}{l}\text { Extraction } \\
\text { method }\end{array}$ & Complications \\
\hline Peng (10) & 2011 & 1 & 68 & NA & Erotic & Difficult & Anal & Bottle & $12 \times 6 \times 6$ & 36 & SA/TA & No \\
\hline \multirow{2}{*}{ Wang (11) } & & & 68 & Widowed & Erotic & Difficult & Anal & Bottle & $5 \times 2.5$ & 72 & SA/TA & No \\
\hline & & & 65 & Widowed & Erotic & Difficult & Anal & Rolling pin & $25 \times 2.5$ & 20 & SA/TA & No \\
\hline Shen (13) & 2006 & 1 & 68 & NA & Treatment & NA & Anal & Bottle & 4 & 4 & SA/TA & No \\
\hline Li (14) & 2007 & 1 & 79 & NA & NA & NA & Anal & Bottle & 6 & 48 & GA/LA & No \\
\hline Zeng (15) & 2013 & 1 & 83 & NA & NA & Difficult & Anal & Bottle & NA & 2 & SA/TA & No \\
\hline $\mathrm{Ma}(16)$ & 2013 & 1 & 70 & Married & Treatment & General & Anal & $\begin{array}{l}\text { Prostate } \\
\text { massager }\end{array}$ & NA & 48 & $\begin{array}{c}\text { NOA/TA } \\
\text { (CO) }\end{array}$ & No \\
\hline Deng (19) & 2009 & 1 & 65 & NA & NA & NA & Anal & Bottle & $20 \times 5$ & 72 & SA/TA & No \\
\hline \multirow[t]{3}{*}{ Guo (20) } & 2003 & 3 & 63 & NA & Erotic & Difficult & Anal & Bottle caps & $5 \times 3$ & 112 & SA/TA & No \\
\hline & & & 84 & NA & Erotic & Difficult & Anal & Bottle caps & $5 \times 4 \times 3$ & 10 & SA/TA & No \\
\hline & & & 65 & NA & Erotic & Difficult & Anal & Screwdriver & $32 \times 15 \times 5$ & 3 & NOA/TA & No \\
\hline \multirow[t]{2}{*}{ Han (21) } & 2010 & 2 & 64 & Single & Erotic & Difficult & Anal & Bottle & $18 \times 3$ & 72 & NOA/TA & No \\
\hline & & & 72 & Single & Erotic & Difficult & Anal & Battery & $3 \times 1.5$ & 48 & NOA/TA & No \\
\hline Guo (22) & 2007 & 1 & 69 & NA & Erotic & Difficult & Anal & Stick & $28 \times 3.5$ & 72 & $\begin{array}{c}\text { NOA/TA } \\
\text { (CO) }\end{array}$ & No \\
\hline Li (23) & 2011 & 1 & 74 & NA & Swallowed & NA & Oral & Duck bone & $3.5 \times 1.8$ & 168 & SA/TA & No \\
\hline \multirow{7}{*}{ Caliskan (7) } & & & 60 & NA & Erotic & NA & Anal & Bottle caps & 8 & NA & SA/TA & NA \\
\hline & & & 66 & NA & Erotic & NA & Anal & Vibrators & 4 & NA & SA/TA & NA \\
\hline & & & 64 & NA & Erotic & NA & Anal & Plastic pipe & 5 & NA & SA/TA & NA \\
\hline & & & 65 & NA & Erotic & NA & Anal & Salt box & 3 & NA & GA/LA & NA \\
\hline & & & 65 & NA & Erotic & NA & Anal & Toothpick box & 5 & NA & GA/LA & NA \\
\hline & & & 79 & NA & Erotic & NA & Anal & Eggplant & 10 & NA & Death & Death \\
\hline & & & 81 & NA & Erotic & NA & Anal & Bottle & 7 & NA & NOA/TA & No \\
\hline Shimizu (25) & 2014 & 1 & 74 & NA & Swallow & NA & Oral & Barb & NA & 720 & GA/LA & Infection \\
\hline $\begin{array}{l}\text { Romera } \\
\text { Barba (26) }\end{array}$ & 2017 & 1 & 68 & NA & NA & NA & Anal & Screwdriver & NA & NA & SA/TA & No \\
\hline Kumar (27) & 2001 & 1 & 69 & Married & Treatment & NA & Medical & Toothbrush & NA & NA & NOA/TA & No \\
\hline \multirow[t]{2}{*}{ Cawich (28) } & 2017 & 2 & 83 & NA & Medical & NA & Medical & Pen $\times 3$ & NA & NA & GA/LA & No \\
\hline & & & 60 & NA & Violence & NA & Anal & Bottle & NA & NA & NOA/TA & No \\
\hline
\end{tabular}

NA, not available; SA, with spinal anesthesia; NOA, no anesthesia; GA, general anesthesia; LA, laparotomy; TA, transanal; CO, colonoscopy. 
following categories: everyday items, food, and sexual articles. The first category accounted for most rectal foreign bodies, inserted primarily in the pursuit of pleasure and partly for unexplained reasons. Sexual articles had been inserted primarily in the pursuit of pleasure. The largest rectal foreign body was a $77-\mathrm{cm}$ long steel rod, and the smallest visible bodies were granuloma formations from dental and vegetable residues.

In the Chinese group of patients, there were 3 cases of rectal foreign bodies that had been swallowed, passed through the gastrointestinal tract, and held up in the rectum, including a jujube seed, a duck bone, and a fishbone. In addition, there were 17 cases of rectal foreign bodies inserted through the anus. Most of the rectal foreign bodies in this group were everyday items or sexual articles. No iatrogenic rectal foreign bodies were found. Among the non-Chinese group of patients, there was 1 case of a swallowed rectal foreign body and 14 cases of anally inserted rectal foreign bodies, most of which were household articles, including screwdrivers and various bottles. There were no significant differences in foreign body sources between the two groups $(\mathrm{P}>0.05)$ (Figure 2A). Further analysis of the sources of the rectal foreign bodies was carried out. We found that the oral rectal foreign bodies in both groups of patients were primarily sharp foodstuffs, such as fishbones, while the anally inserted rectal foreign bodies were primarily everyday items. Patients who had used sexual objects were mainly nonChinese and those with a high degree of education.

\section{Reason of rectal foreign bodies}

The most common reason for a foreign body being in the rectum was for erotic purposes, although occasionally, there were involuntary insertions. It should be noted that a small number of drug runners were included in the cohort. Sharp foodstuffs were the most common oral rectal foreign bodies.

We found that in $60 \%$ of the Chinese cases and $66.7 \%$ of the non-Chinese cases, the foreign bodies had been inserted into the rectum for erotic stimulation and sexual gratification (Figure 2B). Analysis of the shape and texture of the rectal foreign bodies in the two groups showed that blunt foreign bodies and non-fragile foreign bodies accounted for a higher proportion of the rectal foreign bodies than their sharp or fragile counterparts (Figure 2C,2D).

\section{Management of rectal foreign bodies}

The methods used to retrieve the various rectal foreign bodies were also analyzed, as were any associated complications. In the Chinese group of patients, transanal removal under local anesthesia was the primary retrieval method. Most rectal foreign bodies in the Chinese group of patients were successfully removed transanally with local anesthesia, with only a small proportion requiring general anesthesia and abdominal laparotomy. The differences between the Chinese and non-Chinese groups were statistically significant for anesthesia and surgery $(\mathrm{P}=0.036$ and $\mathrm{P}=0.028$, respectively) (Figure $2 E, 2 F$ ). However, although one non-Chinese patient died due to the necrosis of his intestinal mucosal tissue and a systemic infection caused by a lengthy treatment, there were no significant differences in the incidence of complications $(\mathrm{P}=0.383)$ (Figure 2G).

\section{Clinical characteristics and management of rectal foreign body patients in Tangdu Hospital}

In addition to the retrieved studies, data from 8 patients admitted to the Tangdu Hospital from 2010 to 2020, for whom complete data were available, are shown in Table 2. These 8 patients included 2 female and 6 male patients with a median age of 58 years. In 5 of the male patients, the reason for inserting a foreign body into the rectum was to stimulate erotic sensation. Of these, 2 had used vibrators (Figure 3A-3C), 1 had used the base of an electric toothbrush (Figure $3 D, 3 E), 1$ had used a ceramic drinking cup, and 1 had used a $30-\mathrm{cm}$ long piece of bamboo (Figure $3 F, 3 G$ ). All these rectal foreign bodies were cylindrically shaped. Other objects that were encountered included a piece of date pit that was stuck to the rectum wall in the case of a 53 -year-old female (Figure $3 H$ ), an intrauterine contraceptive device (IUCD) that had migrated to the rectouterine space in a 57-year-old female (Figure 3I), and a residual staple that had remained in a 34-year-old male after a hemorrhoidectomy.

In this group, the reasons for the foreign body being in the rectum were erotic purposes (5 of the male patients), migration of an intrauterine device (1 female patient), and accidental swallowing ( 1 female patient). All patients in the erotic-purposes group were male, and most of them were single or divorced.

In the 5 patients who had inserted foreign bodies into their rectums for erotic purposes, the diagnoses were verified by asking about their medical history, performing a rectal examination, and carrying out plain $\mathrm{X}$-ray imaging. The patient who had a piece of date pit in her 
A

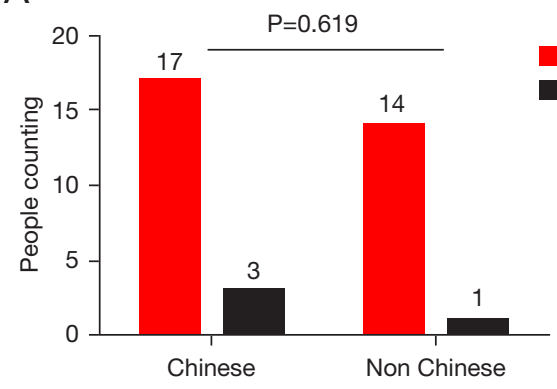

C

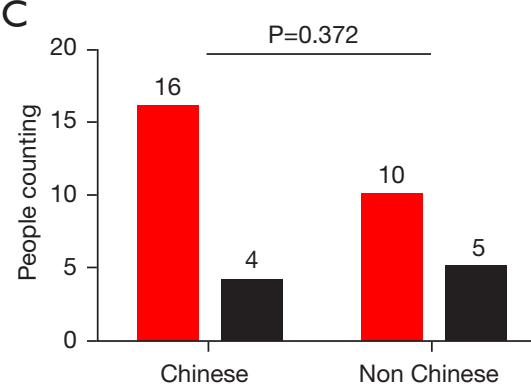

E

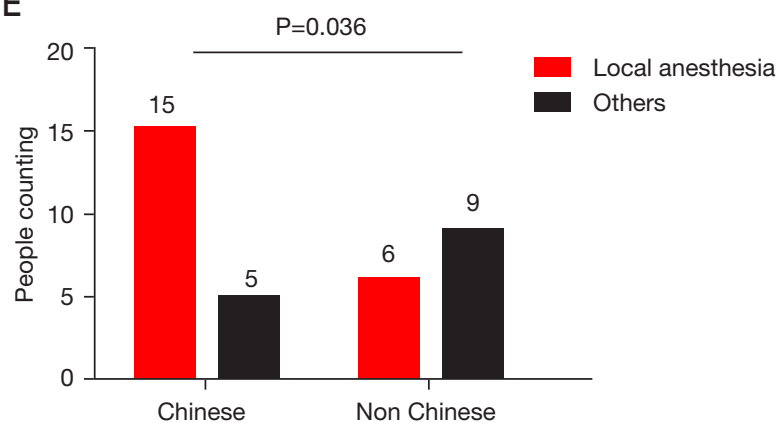

G

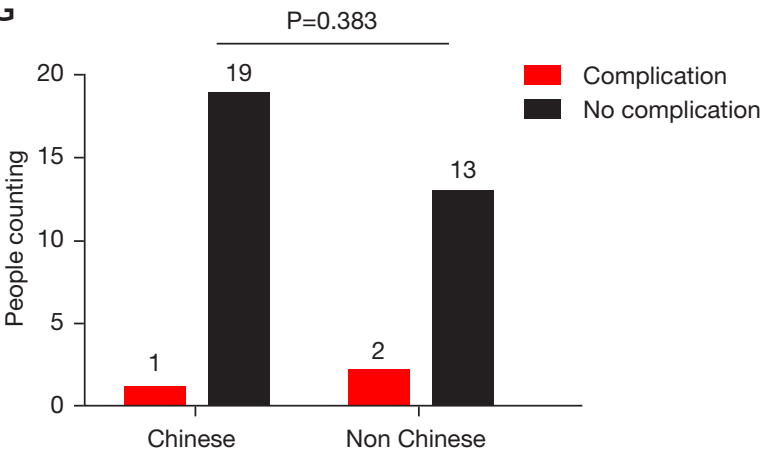

B

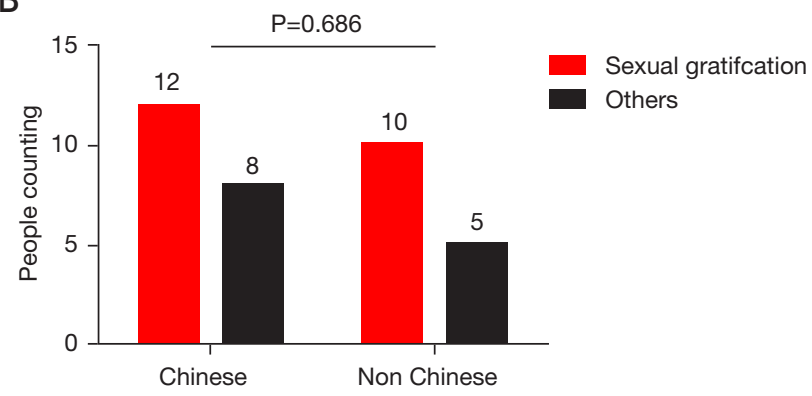

D

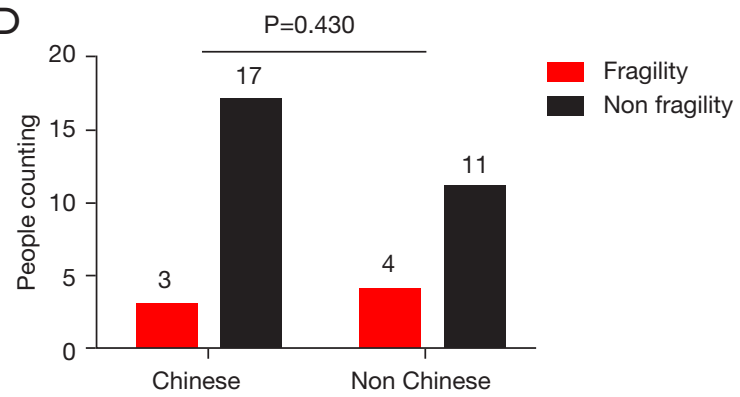

$\mathrm{F}$

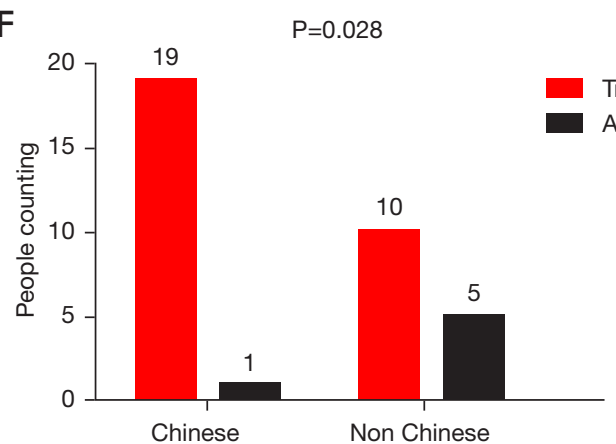

Figure 2 Comparison of the basic information between older Chinese and non-Chinese patients with rectal foreign bodies. (A) Comparison of the sources of rectal foreign bodies between the two groups; (B) comparison of the causes of rectal foreign body between the two groups; (C,D) comparison of the rectal foreign body characteristics between the two groups; (E,F) comparison of the extraction method for the foreign bodies between the two groups; $(\mathrm{G})$ comparison of the postoperative complications between the two groups. 


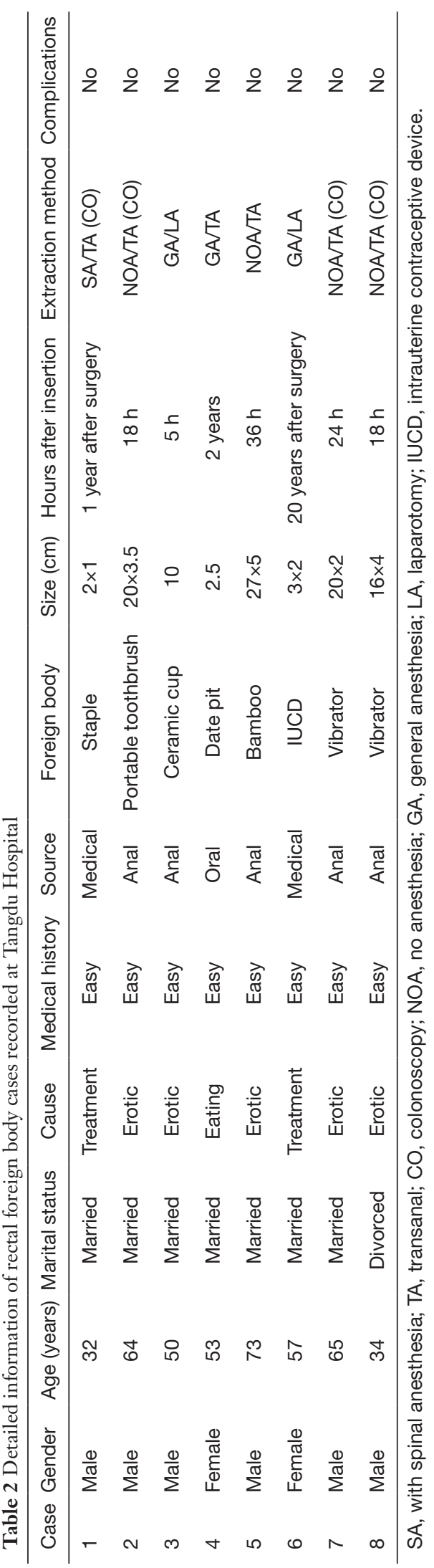

rectum presented pelvic and perianal pain, exacerbated by defecation and diagnosed by a manual rectal examination. In the patient whose IUCD had migrated to her rectum, the diagnosis was confirmed by anamnesis and plain $\mathrm{X}$-ray imaging. The patient with the residual staple presented with pain upon passing stools and was diagnosed during an anoscope examination.

In the clinical treatments, we successfully removed a piece of bamboo approximately $30 \mathrm{~cm}$ in length from the rectum of a patient who had inserted it for erotic purposes. The removal was carried out with surgical forceps while the patient applied increased abdominal pressure. In another case, the rectal foreign body used for erotic purposes could not be extracted even with a laparotomy and bimanual manipulation, and a colostomy was performed. The patient was followed up 3 months after the operation, and no complications were observed. For the other 3 patients who had inserted a foreign body for erotic purposes, a rectoscopy was performed, or the object was removed using surgical forceps under a spinal or general anesthesia in the general endoscopy room at Tangdu Hospital. Attempts to remove the rectal foreign bodies via colonoscopy were successful in the remaining 3 patients. All patients recovered without any complications after the aggressive clinical treatment.

\section{Discussion}

In the past, many studies have focused on the diagnosis, clinical diagnosis, and treatment of rectal foreign bodies (29-34), while few articles have studied the condition from the perspective of the psychological and sexual needs of older male patients. This paper reviewed studies on rectal foreign bodies and combined the analysis with cases of rectal foreign bodies at Tangdu Hospital. The case data were analyzed statistically according to the patients' general characteristics, the source, type, size, and purpose of the rectal foreign bodies, hours after insertion, treatment method, prognosis, and outcome. The patients' ethnicity (Chinese or non-Chinese) and the proportion of older male patients in the study population were also analyzed.

Based on a comprehensive analysis of the literature, we found that clinical treatment methods and prognosis differed according to the size, type, and source of foreign bodies, to their clinical manifestations, and their source. For example, oral rectal foreign bodies were primarily caused by improper eating, or overeating, resulting in the accumulation of foreign bodies in the ampullary of the rectum or by the ingestion of sharp foreign bodies which 

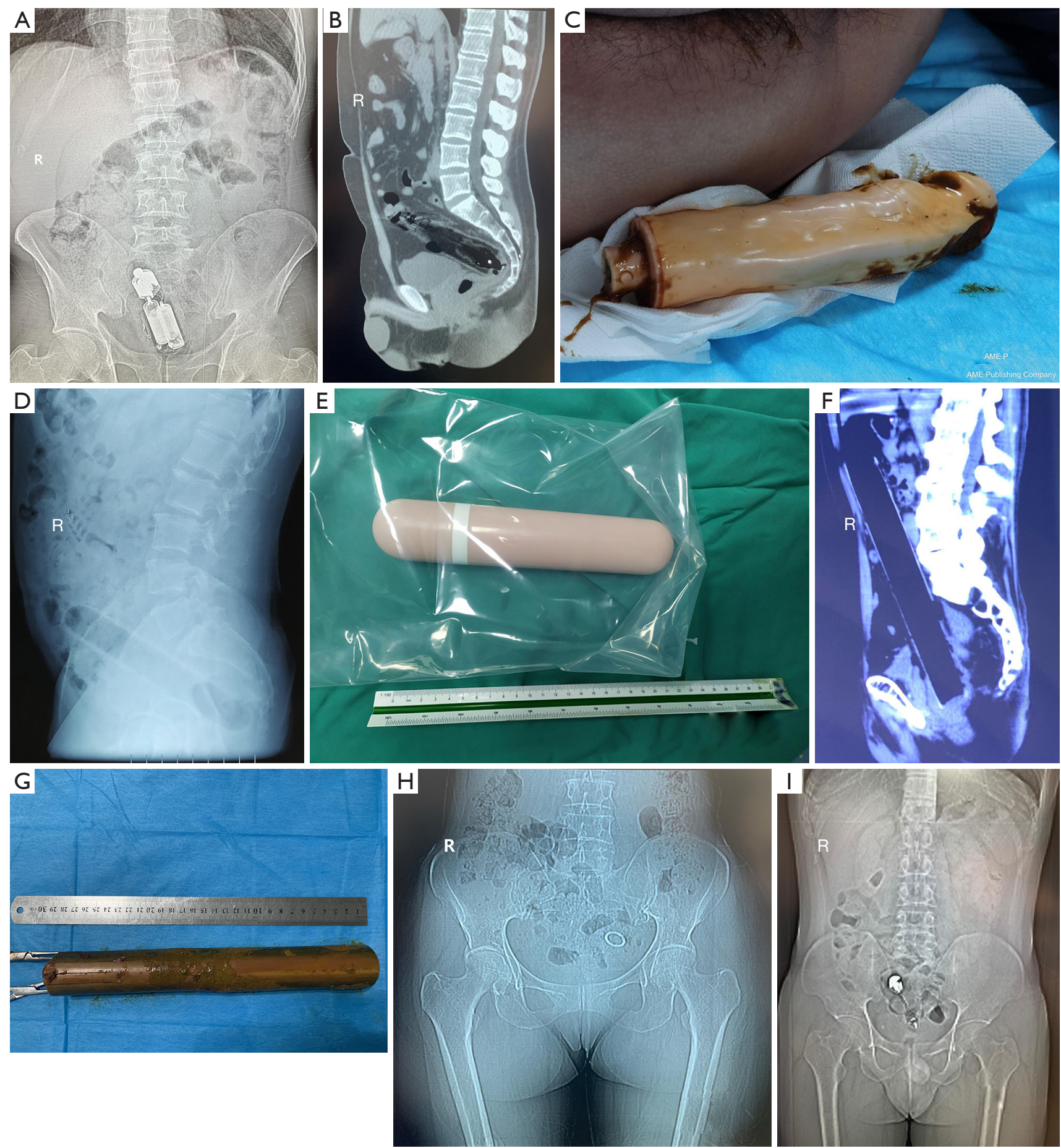

Figure 3 Rectal foreign bodies and imaging pictures. (A-C) Images of vibrators and the physical object in 2 cases; (D,E) image of an electric toothbrush and the physical object in 1 case; $(\mathrm{F}, \mathrm{G})$ image of a $30-\mathrm{cm}$ long piece of bamboo and the physical object in $1 \mathrm{case}$; $(\mathrm{H})$ a piece of date pit image that was stuck to the rectum wall in a 53-year-old female patient; (I) image of an IUCD that had migrated to the rectouterine space in a 57-year-old female patient. IUCD, intrauterine contraceptive device. 
could not be discharged after piercing the rectum wall. The volume of this type of foreign body was generally small, and most oral foreign bodies were discharged through the anus after $4-5$ days $(35,36)$. However, in cases where the transoral rectal foreign body was $\geq 5 \mathrm{~cm}$ in circumference and $\geq 12 \mathrm{~cm}$ in length, hooked, barbed, sharp, polygonal, or small and abundant, it was not easy to discharge and often required surgical intervention (37). The most common source of rectal foreign bodies was anal insertion, primarily due to the patient's desire to relieve anorectal symptoms or masturbate. Some patients accidentally inserted an object and could not remove it, while others suffered an accidental injury, where the object was forcibly inserted through the anus. The volume of this type of foreign body was generally large, and most of the anal rectal foreign bodies caused abdominal pain, perianal pain, rectal bleeding, or intestinal obstruction (9). Many different types of objects were found in the rectum, including sex toys (such as vibrators), batteries, light bulbs, candles, glass cups, wine bottles, metal or wooden objects, fruit and vegetables (such as cucumbers), aerosol cans and their lids, illegal drugs, and unusually large objects, such as soda or beer bottles (37-39). Rectal foreign bodies often cause mucosal edema, tearing, and bleeding in the rectum and intestine wall. Patients who are not treated early often develop perforation and peritonitis, leading to septic shock.

Although the type of study and the number of patients included in this review were limited, we found that a large proportion of older male patients were sexually motivated and that this trend is increasing. We also found that the types of objects used in this way often provoked more serious clinical symptoms, creating challenges for the clinical diagnosis and treatment of these patients (40). As a result of our research, we believe that recognizing and providing for the sexual needs of older people, especially older men, is an issue that requires greater social awareness and wider attention.

This study has two levels of significance. The first is theoretical. To date, there have been few academic studies on the survival status and sexual psychoanalysis of older men from the perspective of their behavior and even fewer studies analyzing rectal foreign bodies from a sexual perspective. This review evaluated studies related to rectal foreign bodies in older men. Based on our analysis, summaries of these studies, and induction we understood the importance of acknowledging human sexual needs and learning about the sexual psychology of the elderly. We also identified research gaps, thus providing ideas for further investigation (3). In addition, we found that types of rectal foreign object may be related, to some degree, to a person's level of education and socio-cultural environment. For example, we found that patients with sexual objects as rectal foreign bodies were usually those with a higher level of education or those who lived in an urban environment. In contrast, patients living in rural areas for a long time or those who were widowed or living alone tended to have everyday items as rectal foreign bodies.

The second level of the significance of this study is practical. Against the social backdrop of accelerated aging in China, the stereotypical image of the older generation differs from their actual needs. Older people not only need hobbies for leisure and physical maintenance, but they also need emotional comfort and social engagement. At present, there are more rural older people than urban in China. Rural areas tend to have a larger number of lonely older people with lower education levels than urban areas due to backward economic trends in rural areas. Older people in these areas do not have full access to social security and live under poorer material, spiritual, and cultural conditions than those in urban areas. Society pays less attention to the older generations, especially those in the less developed western areas of China. Finally, sexuality is a complex biopsychosocial and spiritual state of mind. Recognizing and dealing with sexual issues is a multidimensional task that should be implemented collaboratively between geriatric health services and the whole society (3).

\section{Conclusions}

In addition to their material and spiritual needs, the physiological needs, particularly the sexual psychological needs of older members of society, so often ignored by society, need greater attention from society and from the media.

\section{Acknowledgments}

The authors appreciate the contributions of the patients who participated in this study.

Funding: None.

\section{Footnote}

Reporting Checklist: The authors have completed the PRISMA reporting checklist. Available at https://atm. amegroups.com/article/view/10.21037/atm-22-103/rc 
Data Sharing Statement: Available at https://atm.amegroups. com/article/view/10.21037/atm-22-103/dss

Conflicts of Interest: All authors have completed the ICMJE uniform disclosure form (available at https://atm. amegroups.com/article/view/10.21037/atm-22-103/coif). The authors have no conflicts of interest to declare.

Ethical Statement: The authors are accountable for all aspects of the work in ensuring that questions related to the accuracy or integrity of any part of the work are appropriately investigated and resolved. This study was approved by the Ethics Committee of the Tangdu Hospital of Air Force Medical University (No. K202009-03) and conducted according to the standards of the Declaration of Helsinki (as revised in 2013). Written informed consent was obtained from all study participants.

Open Access Statement: This is an Open Access article distributed in accordance with the Creative Commons Attribution-NonCommercial-NoDerivs 4.0 International License (CC BY-NC-ND 4.0), which permits the noncommercial replication and distribution of the article with the strict proviso that no changes or edits are made and the original work is properly cited (including links to both the formal publication through the relevant DOI and the license). See: https://creativecommons.org/licenses/by-nc-nd/4.0/.

\section{References}

1. Partridge L, Deelen J, Slagboom PE. Facing up to the global challenges of ageing. Nature 2018;561:45-56.

2. Katz A. The sounds of silence: sexuality information for cancer patients. J Clin Oncol 2005;23:238-41.

3. Williams AC, Reckamp K, Freeman B, et al. Sexuality, lung cancer, and the older adult: an unlikely trio? J Adv Pract Oncol 2013;4:331-40.

4. Dhar HL. Gender, aging, health and society. J Assoc Physicians India 2001;49:1012-20.

5. Goldberg JE, Steele SR. Rectal foreign bodies. Surg Clin North Am 2010;90:173-84, Table of Contents.

6. Rodríguez-Hermosa JI, Codina-Cazador A, Ruiz B, et al. Management of foreign bodies in the rectum. Colorectal Dis 2007;9:543-8.

7. Caliskan C, Makay O, Firat O, et al. Foreign bodies in the rectum: an analysis of 30 patients. Surg Today 2011;41:795-800.

8. Ayantunde AA. Approach to the diagnosis and management of retained rectal foreign bodies: clinical update. Tech Coloproctol 2013;17:13-20.

9. Robertson WJ. 'Believe it or not': the medical framing of rectal foreign bodies. Cult Health Sex 2017;19:815-28.

10. Peng $Y$. Experience in diagnosis and treatment of vitreous rectal foreign bodies caused by adult sexual masturbation. Shanxi Med J 2011;40:374-5.

11. Wang S, Jian Y, Sujian N. Adult sexual masturbation causes rectal foreign body. Zhonghua Nan Ke Xue 2000;16:206-7.

12. Xu R, Li W. Removal of foreign bodies in anal canal and rectum: report of 2 cases. Occupation and Health 2001;17:118.

13. Shen Q. A case of rare rectal foreign body. Chinese Journal of Modern Medicine 2006;8:49.

14. Li S, Chen E. Diagnosis and Management of Colorectal Foreign Bodies. Medical Recapitulate 2007;13:380-2.

15. Zeng W, Li S, Cao Z, et al. One case of rectal foreign body in the elderly. Chinese Journal of Ethnomedicine and Ethnopharmacy 2013;2:62-3.

16. Ma S, Lu Y. Rectal foreign body caused by prostatic massage in chronic nonbacterial prostatitis: a case report. China Medicine and Pharmacy 2013;3:168-9.

17. Zhang R. 3 cases of rectal foreign body caused by sexual masturbation. Journal of Chinese Physician 2002;4:1134.

18. Yan 1, Huang J, Xu W, et al. Experience in diagnosis and treatment of rectal foreign body incarceration caused by sexual masturbation (report of 4 cases). Zhonghua Nan Ke Xue 2011;17:849-51.

19. Deng L, Ma D, Chen B, et al. Large foreign body in rectum in 2 cases. Colorectal and Anal Surgery 2009; 15:427.

20. Guo Y, Li Y, Zhou Y. Foreign body in rectum: report of 10 cases. Chinese Journal of Medical Doctors 2003;1:169-70.

21. Han L. Rectal foreign body in 3 cases. Hebei Medical Journal 2010;32:1663.

22. Guo F, Ding X. Rectal foreign body: report of 3 cases. Ningxia Medical Journal 2007;29:111.

23. Li K. Diagnosis and treatment of rectal foreign body in 21 cases. Chinese Medical Engineering 2011;19:132.

24. Mao L, Huang X. Experience in diagnosis and treatment of high perianal abscess caused by rectal foreign body. Medical Diet and Health 2020;11:103-5.

25. Shimizu T, Harada K, Akazawa S, et al. Identification of the cause of severe skin infection by Fournier transform infrared spectroscopy: a case of Fournier's gangrene caused by fish bone. J Dermatol 2014;41:547-50.

26. Romera Barba E, González-Costea Martínez R, Navarro 
García MI, et al. Foreing body of the rectum. Cir Esp 2017;95:169.

27. Kumar M. Don't forget your toothbrush! Br Dent J 2001;191:27-8.

28. Cawich SO, Thomas DA, Mohammed F, et al. A Management Algorithm for Retained Rectal Foreign Bodies. Am J Mens Health 2017;11:684-92.

29. Wu JH, Zhang HY, Xia Y, et al. A novel technique for minimally invasive removal of a foreign body in the rectal wall. Tech Coloproctol 2018;22:313-7.

30. Bakheit IA, Elhasan GAB, Salih MA. A case of impacted foreign body in the rectum that was extracted using size 24 Foley catheter. Int J Surg Case Rep 2020;66:146-8.

31. Bulte JP, Clermonts SHEM, Zimmerman DDE. Antegrade impalement of the rectum by a foreign body: a case report of a successful transanal extraction using the transanal single port (TAMIS) technique. Tech Coloproctol 2019;23:175-8.

32. Gajjar RA, Gupta PB. Foreign body in the rectum: A challenge for the emergency physician. J Family Med Prim Care 2016;5:495-7.

33. Gentile M, Cestaro G, Di Filippo G, et al. Successful transanal removal of unusual foreign body self-inserted in the rectum A case report and review of literature. Ann Ital

Cite this article as: Yang Z, Xin P, Zhou S, Zhou C, He X, Bao G. Systematic review of rectal foreign bodies in older men: humanistic care and a novel challenge for society. Ann Transl Med 2022;10(4):164. doi: 10.21037/atm-22-103
Chir 2019;90:88-92.

34. Jung EJ, Ryu CG, Kim G, et al. Impaction of a foreign body in the rectum by improper use of a (electronic) massager: a case report. J Korean Soc Coloproctol 2010;26:298-301.

35. Sajjad H, Paish LM. Rectum Foreign Body Removal. StatPearls. Treasure Island (FL); 2020.

36. Tatar C, Karşıdağ T, Hut A. Successful endoscopic removal of a foreign body in the rectum. Turk J Gastroenterol 2014;25:442-3.

37. Ye H, Huang S, Zhou Q, et al. Migration of a foreign body to the rectum: A case report and literature review. Medicine (Baltimore) 2018;97:e11512.

38. Narjis Y, Rabbani K, Hakkou K, et al. Foreign body of the rectum: An unusual case. J Emerg Trauma Shock 2010;3:306.

39. Rodrigues GS, Lobo DN. A foreign body in the rectum. Indian J Surg 2010;72:74.

40. Vahdati SS, Shahri SA, Habibollahi P, et al. Medical image. Anal pain: think about foreign body in the rectum. N Z Med J 2012;125:96-9.

(English Language Editor: L. Roberts) 